\title{
A Cross - Sectional Study to Assess the Awareness of PCPNDT Act and the Term Sex-Ratio among Married Women of Cosmopolitan City of Central India
}

\author{
Dr Deepa Raghunath ${ }^{1}$, Dr Anand Kumar Patidar ${ }^{2}$, Dr Sanjay Dixit ${ }^{3}$, Dr Harish Shukla ${ }^{4}$ \\ Kriti Sharma $^{5}$, Mohit Gothwal ${ }^{6}$, Mrinal Chatterjee ${ }^{7}$, Mudit Maheshwari ${ }^{8}$ \\ Nikhil Mishra ${ }^{9}$ \\ ${ }^{1}$ Associate Professor, ${ }^{2}$ Resident, ${ }^{3}$ Prof.\&HOD of Community Medicine \\ 1,2,3,4,5,6,7,8,9 MGM Medical College Indore MP India \\ Corresponding Author \\ Dr Anand Kumar Patidar \\ Resident, MGM Medical College Indore MP India
}

\begin{abstract}
Background: The Pre-Conception and Pre-Natal Diagnostic Techniques (PC \& PNDT) Act, is an Act of the Parliament of India enacted to stop female feticide and arrest the declining sex ratio in India. It is a legislation to curb the abhorrent practice of sex determination and sex selection, which has its roots in India's long history of strong patriarchal influence in all spheres of life.

Methods: An observational study done for 3 month in tertiary care government medical college, fertility clinics and residential areas of Indore city. 270 married women of age group 18-40 yrs of different socioeconomic class and educational status were interviewed by using Pre designed semi-structured questionnaire for assessing the awareness regarding PCPNDT Act.

Results: In this study about 73\% had awareness about PCPNDT act and 63\% were aware about the term sex ratio however the knowledge about the meaning of the term sex ratio were slight low(54.8\%).Only 48\% had knowledge about the person responsible for gender of the child and about $60 \%$ had awareness with regards to female feticide.

Conclusion: Majority of the study population were aware about the PCPNDT act, female feticide and sex ratio.

Keywords: PCPNDT act, Sex ratio, Married women.
\end{abstract}

\section{Introduction}

The Pre-Conception and Pre-Natal Diagnostic Techniques (PC \& PNDT) Act, is an Act of the Parliament of India enacted to stop female feticide and arrest the declining sex ratio in India. The main purpose of enacting the act is to ban the use of sex selection techniques after conception and prevent the misuse of prenatal diagnostic technique for sex selective abortion. According to this law, No laboratory or centre or clinic will conduct any test including ultrasonography for the purpose of determining the sex of the foetus. No 


\section{JMSCR Vol||06||Issue||05||Page 904-909||May}

person, including the one who is conducting the procedure as per the law, will communicate the sex of the foetus to the pregnant woman or her relatives by words, signs or any other method ${ }^{(\mathbf{1})}$. It is a legislation to curb the abhorrent practice of sex determination and sex selection, which has its roots in India's long history of strong patriarchal influence in all spheres of life ${ }^{(2)}$. The sex ratio is the ratio of females to thousand males in a population. According to 2011 census, this ratio is 940 women for every 1000 men $^{(3)}$. In India, the Child Sex Ratio is defined as the number of females per thousand males in the age group 0-6 years in a human population. As per the Census, 2011 the child sex ratio (0-6 years) has shown a decline from 927 females per thousand males in 2001 to 919 females per thousand males in $2011^{(4)}$. India has several social legislations directed at changing social behaviour and practices. We have laws that prohibit practices such as dowry, child marriage and sati. The PCPNDT Act is different from other social legislations because it does not involve only change in social behaviour and practices. It also demands ethical medical practice and the regulation of medical technologies that have the potential to be misused ${ }^{2}$. The study principally aims to find out about the awareness regarding the Act and sex ratio and acknowledge its importance in the general population of Indore.

\section{Methodology}

It is an observational study done in 3 month of study period (September 2016-December 2016) in Indore city. simple random sampling techniques was used for data collection. Study site included were tertiary care government medical college, fertility clinics and residential areas of Indore city. 270 married women of age group 18-40 yrs of different socioeconomic class were interviewed by using Pre designed semi-structured questionnaire which assessed the awareness regarding PCPNDT Act. Women Not within the age group and who did not give consent were excluded. Written informed consent was taken from every individual before filling the questionnaire. All the participants were informed about right to quit at any time without need for any explanation. Data collected and entered in Microsoft Excel sheet. Data were analyzed using SPSS version 20 using appropriate statistical tests like Chi-square test.

\section{Results}

The present study was conducted to assess awareness about PCPNDT act and sex Ratio among 270 married women between 18-40 yrs of age group of Upper, Middle and Lower socioeconomic class and different education status as shown in Table 1 .

Table 1: Showing distribution of married women according to their demographic profile

\begin{tabular}{|l|lc|}
$\begin{array}{l}\text { Demographic } \\
\text { profile }\end{array}$ & Options & No. of Participants \\
\hline Age of Participants & $20-24$ yrs & $51(18.8 \%)$ \\
& $25-29$ yrs & $99(36.7 \%)$ \\
& $30-34$ yrs & $90(33.3 \%)$ \\
& $35-39$ yrs & $30(11.1 \%)$ \\
\hline Education & Up to Middle school & $55(20.4 \%)$ \\
& Up to High-secondary & $84(31.1 \%)$ \\
\hline Socio-economic \\
class & Up to Graduate and above & $131(48.5 \%$ \\
& Upper & $90(33.3 \%)$ \\
& Middle & $90(33.3 \%)$ \\
& Lower & $90(33.3 \%)$ \\
\hline
\end{tabular}

Knowledge and awareness assessment regarding PCPNDT act and Sex ratio has shown in Table 2. 


\section{JMSCR Vol||06||Issue||05||Page 904-909||May}

Table 2: Showing awareness of married women regarding PCPNDT act and sex ratio

\begin{tabular}{|l|c|c|}
\multicolumn{1}{|c|}{ Parameters } & \multicolumn{2}{c|}{ Responses( N=270) } \\
\hline Awareness regarding PCPNDT Act & Yes & No \\
\hline Awareness about the term Sex ratio & $197(73 \%)$ & $73(27 \%)$ \\
\hline Knowledge regarding meaning of the term 'Sex Ratio' & $168(63 \%)$ & $102(37 \%)$ \\
\hline Knowledge regarding person responsible for the gender of child & $148(54.8 \%)$ & $122(45.2 \%)$ \\
\hline Awareness regarding female feticide & $130(48 \%)$ & $140(52 \%)$ \\
\hline Gender Preference for 1st child & $161(59.6 \%)$ & $109(40.4 \%)$ \\
\hline Knowledge regarding possibility of sex determination & $73((27 \%)$ & $197(73 \%)$ \\
\hline Awareness regarding law against Sex Determination & $178(66 \%)$ & $92(34 \%)$ \\
\hline
\end{tabular}

In this study about $73 \%$ had awareness about PCPNDT act and $63 \%$ were aware about the term sex ratio however the knowledge about the meaning of the term sex ratio were slight low(54.8\%). Only $48 \%$ had knowledge about the person responsible for gender of the child and about $60 \%$ had awareness with regards to female feticide. In this study gender preference was found only in $27 \%$. About $66 \%$ were aware that there is possibility of sex determination and $72 \%$ had knowledge that there is law against sex determination.

In this study there were significant difference was found in different socioeconomic status regarding knowledge about the term sex ratio, person responsible for gender of sex child, awareness about female feticide, knowledge regarding possibility of sex determination and law against sex determination and no significant difference was found regarding gender preference as shown in Table 3.

Table 3: Showing awareness regarding PCPNDT act and sex ratio in married women of different socioeconomic status

\begin{tabular}{|l|c|c|c|c|}
\hline Variable & \multicolumn{3}{|c|}{ Socio-economic status } & P value \\
\hline $\begin{array}{l}\text { Knowledge regarding meaning of the } \\
\text { term sex ratio }\end{array}$ & $60(66.6 \%)$ & $52(57.8 \%)$ & $36(40 \%)$ & 0.0012 \\
\hline Person responsible for Sex of Child & $58(64.4 \%)$ & $40(44.4 \%)$ & $32(35.6 \%)$ & $\begin{array}{c}0.0003 \\
X^{2}=15.78\end{array}$ \\
\hline Female Feticide Awareness & $64(71.1 \%)$ & $59(65.6 \%)$ & $38(42.2 \%)$ & $\begin{array}{c}0.0019 \\
X^{2}=12.44\end{array}$ \\
\hline Awareness about term Sex Selection & $50(55.5 \%)$ & $42(46.7 \%)$ & $28(31.1 \%)$ & $\begin{array}{c}0.0037 \\
X^{2}=11.16\end{array}$ \\
\hline $\begin{array}{l}\text { Knowledge regarding Possibility } \\
\text { of Sex Determination }\end{array}$ & $69(76.7 \%)$ & $63(70 \%)$ & $46(51.1 \%)$ & $\begin{array}{c}0.0008 \\
X^{2}=14.08\end{array}$ \\
\hline Aware about enacting PCPNDT act & $57(63.3 \%)$ & $42(46.7 \%)$ & $38(42.2 \%)$ & $\begin{array}{c}0.011 \\
X^{2}=8.92\end{array}$ \\
\hline Gender Preference for 1st child & $27(30 \%)$ & $29(32.2 \%)$ & $17(18.9 \%)$ & $\begin{array}{c}0.24 \\
X^{2}=2.78\end{array}$ \\
\hline
\end{tabular}

In this study there were significant difference was found in different education status regarding knowledge about the term sex ratio, person responsible for gender of sex child and knowledge regarding possibility of sex determination .There were no significant difference was found regarding awareness about female feticide and Knowledge regarding law against Sex Determination as shown in Table 4. 


\section{JMSCR Vol||06||Issue||05||Page 904-909||May}

Table 4: Showing awareness regarding PCPNDT act and sex ratio in married women of different Educational status

\begin{tabular}{|c|c|c|c|c|}
\hline \multirow[t]{2}{*}{ Variable } & \multicolumn{3}{|c|}{ Educational status } & \multirow[t]{2}{*}{ P value } \\
\hline & $\begin{array}{l}\text { Up to Middle } \\
\text { school } \\
(\mathrm{N}=55)\end{array}$ & $\begin{array}{l}\text { Up to High- } \\
\text { secondary } \\
(\mathrm{N}=84)\end{array}$ & $\begin{array}{ll}\text { Up to } & \text { Graduate } \\
\text { and } & \text { above } \\
(\mathrm{N}=131) & \end{array}$ & \\
\hline $\begin{array}{l}\text { Knowledge regarding meaning of } \\
\text { the term sex ratio }\end{array}$ & $15(27.2 \%)$ & $34(40.4 \%)$ & $60(45.8 \%)$ & $\begin{array}{l}0.010 \\
X^{2}=9.13\end{array}$ \\
\hline $\begin{array}{l}\text { Person responsible for } \\
\text { Sex of Child }\end{array}$ & $25(45.4 \%)$ & $40(47.6 \%)$ & $75(57.2 \%)$ & $\begin{array}{l}0.04 \\
X^{2}=6.01\end{array}$ \\
\hline Female Feticide Awareness & $38(69 \%)$ & $56(66.7 \%)$ & $101(77 \%)$ & $\begin{array}{l}0.21 \\
X^{2}=3.11\end{array}$ \\
\hline $\begin{array}{l}\text { Knowledge regarding possibility of } \\
\text { sex determination }\end{array}$ & $21(38.1 \%)$ & $48(57.1 \%)$ & $90(68.7 \%)$ & $\begin{array}{l}0.0005 \\
X^{2}=15.06\end{array}$ \\
\hline $\begin{array}{l}\text { Knowledge regarding law against } \\
\text { Sex Determination }\end{array}$ & $35(63.6 \%)$ & $40(47.6 \%)$ & $75(57.2 \%)$ & $\begin{array}{l}0.15 \\
X^{2}=3.75\end{array}$ \\
\hline
\end{tabular}

\section{Discussion}

Despite the strict law against PCPNDT and various government schemes for female child there is disappointing sex ratio in India varies from states to state. This study hence done to assess the knowledge and awareness regarding PCPNDT act and sex ratio in 270 married women of age group between 20-40 yrs( Mean $=28.7$, SD $=4.78)$ of different educational and socioeconomic status.

In our study $73 \%$ participant had awareness about PCPNDT act while another study done by Sonal R Deshpande et al GMC Nagpur (2014) ${ }^{(5)}$ showed that only $65 \%$ and study of Pallavi R. Shidhaye et al ${ }^{(6)}$ only $34 \%$ were aware about the act. In our study $63 \%$ were aware about the term sex ratio however knowledge about what its actual means was found only in 55\%. In our study $48 \%$ participant had knowledge about the person responsible for the gender of the child i.e. Biologically father is responsible for sex of the child, $20 \%$ states that mother and father both are responsible for it and about $18 \%$ thought that God is responsible for it. In our study about $66 \%$ had knowledge that there is possibility of sex determination before birth of child by present technology which was similar in study of Pallavi R. Shidhaye et $\mathrm{al}^{(6)}$ where $73 \%$ women had knowledge about it. and in study of Puri $\mathrm{S}$ et al ${ }^{(7)}$ $11.66 \%$ participants had knowledge regarding it. In our study $72 \%$ were aware that there is law against sex determination. This finding is similar in the study done by Nitin kumar et al ${ }^{(8)}(2014)$ where $74.4 \%$ participants said that prenatal sex determination is a punishable offence. While in study of Sonal R Deshpande et al ${ }^{(5)} 42.5 \%$ knew that antenatal sex determination is punishable under law and study of Puri $\mathrm{S}$ et $\mathrm{al}^{(7)}$ only $16 \%$ were aware that it was punishable under the law.

In our study there was significant difference was found in knowledge of different socioeconomic class regarding actual meaning of the term sex ratio, Person responsible for gender of Child, Female feticide, Awareness about term Sex Selection, Regarding possibility of Sex determination, and about enacting PCPNDT act i.e. Upper socioeconomic class women were more aware about these in compared to middle and lower socioeconomic class.

There was no significant difference was found about gender preference in women of different socioeconomic class. Majority were happy with both the sex of the child whether boy or girl don't bother. This was similar to the study done by Sonal R Deshpande et al where no association was found between literacy status and socioeconomic class of the study subjects and preference to male child as opposed to the study by Srivastav et al ${ }^{(9)}$ and Khatri $\mathrm{M}$ et $\mathrm{al}^{(10)}$ where unawareness regarding PCPNDT Act and preference for male child was significantly associated with the literacy status of females. 


\section{JMSCR Vol||06||Issue||05||Page 904-909||May}

In our study it was found that awareness regarding actual meaning of the term sex ratio, Person responsible for gender of Child and Possibility of Sex determination is improved with educational status of the women. Awareness about female feticide and possibility of sex determination did not vary significantly with education level. While in study done by Vadera BN et $\mathrm{al}^{(11)}$ showed that the awareness of consequences of female feticide increases with literacy status.

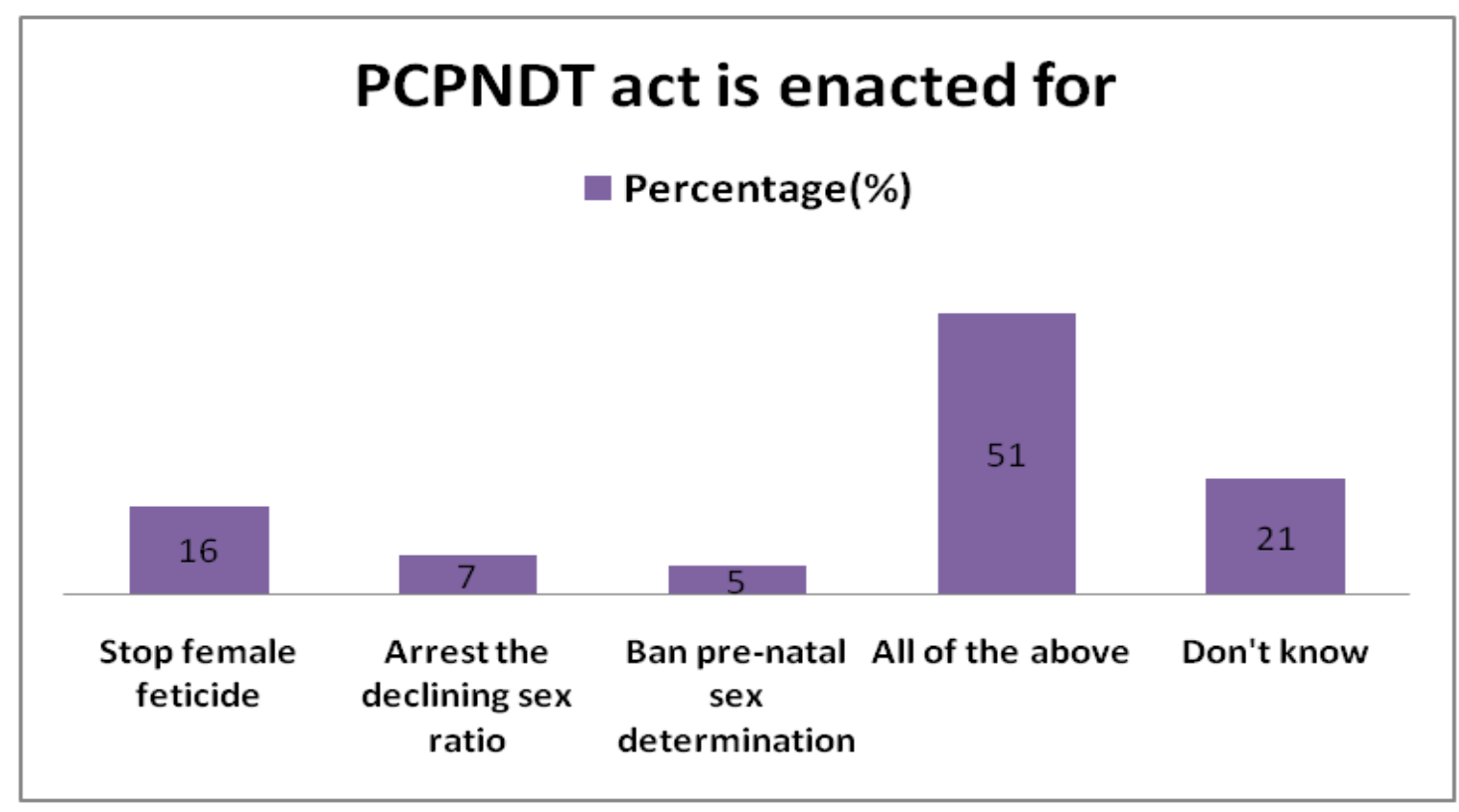

Figure 1: Bar diagram showing knowledge about PCPNDT act

In our study $51 \%$ participant had knowledge that PCPNDT act is enacted to stop female feticide, arrest the declining sex ratio and for banning of pre-natal sex determination, $21 \%$ don't know about the act and $28 \%$ had partial knowledge about it as shown in figure 1.

In our study $65 \%$ women agreed that there is coercion on mother to produce a male child in Indian society while $28 \%$ were disagreed and $7 \%$ were neutral about it.

\section{Conclusion}

Based on the results of our study we concluded that majority of the study population were aware about the PCPNDT act, female feticide and sex ratio. However knowledge difference was found regarding the term sex ratio, person responsible for sex of the child in different socioeconomic groups and educational status. Surprisingly no gender preference was found between different socioeconomic and educational groups.

\section{Recommendations}

(1)The state must use the mass communication media for public education and to spread awareness about the required ethical conduct of medical professionals. (2) Community based awareness about the campaigns like Beti Bachao, Beti Padhao Yojana, Ladli Laxmi Yojana etc.

(3) Women employment, education and empowerment should be paid proper emphasis.

Funding: No funding sources

Conflict of interest: None declared

Ethical approval: The study was approved by the institutional ethics committee

\section{References}

1. https://en.wikipedia.org/wiki/PreConception_and_Pre-Natal_ Diagnostic_Techniques_Act,_1994 PreConception and Pre-Natal Diagnostic Techniques Act ... - Wikipedia

2. [PDF]Sex Selection - Pre-Natal Diagnostic Techniques 


\section{JMSCR Vol||06||Issue||05||Page 904-909||May}

pndt.gov.in/writereaddata/mainlinkfile/File 53.pdf

3. https://en.m.wikipedia.org/wiki/ List of states and union territories of India by sex ratio - Wikipedia

4. http://pib.nic.in/newsite/PrintRelease.aspx ?relid=103437Press Information

Bureau Government of India Ministry of Health and Family Welfare Decline In Child Sex Ratio

5. Awareness and perception regarding PCPNDT Act and gender preference among mothers of under-five attending immunization clinic Sonal R Deshpande1, Pragati G Rathod1, Sharad B Mankar2, Uday W Narlawar1 Int J Med Sci Public Health. 2016; 5(9): 1878-1882

6. Study of knowledge and attitude regarding prenatal diagnostic techniques act among the pregnant women at a tertiary care teaching hospital in Mumbai Pallavi R. Shidhaye, Purushottam A. Giri, Shashikant N. Nagaonkar,1 and Rahul R. Shidhaye J Educ Health Promot. 2012; 1: 36. Published online 2012 Oct 6. doi: $10.4103 / 2277-9531.102049$

7. Puri S, Bhatia V, Swami HM. Gender Preference and Awareness Regarding Sex Determination among Married Women in Slums of Chandigarh. Indian J Community Med. 2007;32:60-2.

8. Awareness and Attitudes Regarding Prenatal Sex Determination, PreConception and Pre-Natal Diagnostic Techniques Act (PCPNDTA) among Pregnant Women inSouthern India 2014 Nithin Kumar,1 B B Darshan,2 Bhaskaran Unnikrishnan,3 Tanuj Kanchan,4 Rekha Thapar, J Clin Diagn Res. 2014 Oct; 8(10): JC09-JC11. Published online 2014 Oct 20.

9. Shrivastava S, Kariwal P, Kapilasrami MC. A community based study on awareness and perception on gender discrimination and sex preference among married women (in reproductive age group) in a rural population of district Bareilly, Uttar Pradesh. Nat J Commun Med. 2011;2:273-6.

10. Khatri M, Acharya R, Sharma G. Knowledge, attitude and practices (KAP) related to Pre-Conception \& Pre-Natal Diagnostic Techniques (PC \& PNDT) Act among the antenatal women in Bikaner. Open Access Scientific Reports 2012;1(1):1-7.

11. Vadera BN, Joshi UK, Unadakat SV, Yadav BS, Yadav S. Study on Knowledge, attitude and practices regarding gender preference and female foeticide among pregnant women. Indian J Community Med. 2007;32:300-1. 